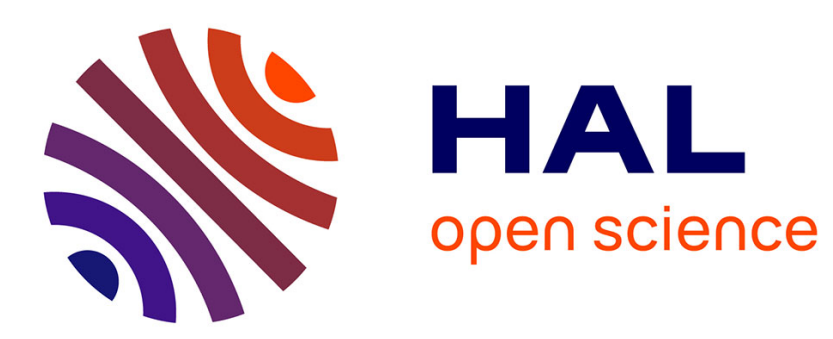

\title{
Picturing the brain from different perspectives: the neuroimaging of early AD.
}

Francis Eustache, Gaël Chételat

\section{To cite this version:}

Francis Eustache, Gaël Chételat. Picturing the brain from different perspectives: the neuroimaging of early AD.. Neuropsychologia, 2008, 46 (6), pp.1595-6. 10.1016/j.neuropsychologia.2008.04.001 . inserm-00494081

\section{HAL Id: inserm-00494081 https://www.hal.inserm.fr/inserm-00494081}

Submitted on 22 Jun 2010

HAL is a multi-disciplinary open access archive for the deposit and dissemination of scientific research documents, whether they are published or not. The documents may come from teaching and research institutions in France or abroad, or from public or private research centers.
L'archive ouverte pluridisciplinaire HAL, est destinée au dépôt et à la diffusion de documents scientifiques de niveau recherche, publiés ou non, émanant des établissements d'enseignement et de recherche français ou étrangers, des laboratoires publics ou privés. 


\section{EDITORIAL}

Picturing the brain from different perspectives: the neuroimaging of early $\mathrm{AD}$

The last 150 years have witnessed dramatic improvements in the field of what we now call Neuropsychology. The description of the clinical and cognitive signs of specific brain diseases, as well as our understanding of normal brain function have been considerably improved, thanks to research ranging from anatomoclinical studies to experimental psychology paradigms applied both to patients with brain lesions and to healthy subjects. In the field of dementia, since Dr Alois Alzheimer presented his first case of the eponymous disorder (Alzheimer, 1907; Jucker, Beyreuther, Haass, Nitsch, \& Christen, 2006) roughly a century ago, studies of Alzheimer's disease (AD) have allowed us to characterize the cognitive deficits associated with this neurodegenerative disease far more accurately, thereby improving its diagnosis. These studies have also informed the modelling of memory (Eustache \& Desgranges, 2008) and other cognitive functions, such as language, executive functions, control of behaviour and social cognition (Hodges, 2006). Research in this area has had a chequered history, with a sixty-year period of relative indifference giving way to a sudden wave of enthusiasm in the early 1980s, bringing together scientists from many disciplines and generating a huge amount of knowledge with a considerable societal impact.

Cognitive neuropsychology has been the driving force behind this reawakening of interest, allowing for a better understanding of the preserved and impaired cognitive processes/systems in the very early stages of different neurodegenerative diseases, through highly informative and comparative approaches. We now know, for instance, that $\mathrm{AD}$ is typically characterized by early and marked deficits in episodic memory, whereas other memory systems (such as procedural memory) remain relatively preserved until a far later stage in the disease (Heindel, Salmon, Shults, Walicke, \& Butters, 1989). Regarding episodic memory, detailed neuropsychological assessments have revealed that deficits not only concern the retrieval of information, but also its encoding (Gainotti \& Marra, 1994). By contrast, memory decline related to normal ageing would appear to stem mainly from retrieval difficulties. These contrasting profiles of memory deficits are particularly important, as they may make it easier to distinguish between normal and pathological ageing. A better understanding of the very early cerebral and cognitive impairments and their mechanisms would contribute to earlier diagnosis of AD and lead to fresh developments in therapeutic intervention strategies. As such, it would constitute a decisive breakthrough from a social, financial and scientific standpoint.

Over the last thirty years, the field of neuropsychology has witnessed considerable developments in cognitive assessments, with the introduction of computerized techniques and virtual reality, together with the emergence of anatomical and functional neuroimaging methods. This decisive shift in methodologies has been parallelled by an impressive growth in our knowledge about cerebral impairments related to brain diseases, including $\mathrm{AD}$. As the disease progresses, the brain changes: it becomes atrophied, its

metabolism declines, its resting-state and task-induced activity drops, amyloid deposits 
accumulate, brain alpha rhythm amplitude decreases, cholinergic neurotransmission is impaired, etc.

Interestingly, AD-associated changes are not solely characterized by declines, as there are also signs that the brain puts up varied forms of resistance to this attack. There is evidence of increased brain activity in some areas, upregulation of certain neurotransmission systems and additional recruitment of relatively preserved brain regions that may reflect compensatory attempts. Over and above the fact that this brings a positive message amidst all the doom and gloom of the pathological events, these enhancements are particularly interesting, as they represent the brain's natural and ecological defence mechanisms in response to injury, which could inspire future pharmacological or nonpharmacological interventions. Moreover, they provide useful information about the physiological mechanisms of brain function and plasticity. Thus, despite the shift in methodologies, neuropsychology continues to pursue the same target as ever, studying brain pathology in order to gain a better understanding not only of the diseased brain but also of normal brain function.

This special issue focuses on early AD, with the specific objective of highlighting the way in which different yet complementary neuroimaging approaches each offer invaluable insight into AD-related brain changes. Although it does not claim to be exhaustive, it does seek to provide a comprehensive overview of the disease, presenting a wide range of points of view via different neuroimaging techniques, from the earliest and most widely-used methods employed to study cognitive deficits, such as EEG, structural and functional MRI and resting-state FDG-PET, to more recent techniques such as diffusion tensor imaging, novel ways of using tried and tested techniques and new data analysis methods, allowing us to explore neuronal integrity and connectivity, specific neurotransmitter systems, and amyloid plaque and tau tangle deposition.

Thus, the profile of early brain atrophy and its progression over the course of AD are detailed in the review by Apostolova et al., as well as in the original papers by Chételat et al., detailing hippocampal changes, and Schott et al., assessing the correlations with neuropsychological decline. Resting-state FDG-PET changes and their relationship with cognitive deterioration are described in the review by Salmon et al. and the study by Giffard et al., while Herholz et al. present an overview of the impairment of cholinergic neurotransmission in the very early stages of AD. The review by Dickerson and Sperling focuses on fMRI findings for the hippocampus in early AD, tackling the notion of compensation, while the original contribution from Trivedi et al. investigates the effect of $\mathrm{AD}$ risk factors on brain activity, analyzing fMRI data from a large sample of cognitively healthy individuals. Liu et al.'s review and Persson et al.'s study focus on the effect of $\mathrm{AD}$ on the default-mode network, adopting several different approaches, including deactivations, resting-state fMRI, functional connectivity and synchrony, illustrating the wealth of this recently developed and extremely promising topic. Structural connectivity impairments due to $\mathrm{AD}$ are studied using diffusion tensor imaging in the paper by Fellgiebel et al., while the original contribution from Babiloni et al. introduces the area of EEG research and illustrates the potential of multimodal neuroimaging approaches. Last but not least, the exciting developments in PET amyloidimaging tracers are explored in the review by Nordberg et al. and in the original research by Villemagne et al., which highlights the relationship between amyloid deposition and cognitive change. 
This attempt to provide an overview of the various manifestations of the disease is just the start of efforts to fit together the different pieces of the jigsaw puzzle in order to gain a more complete picture of the disease that may help us to understand its underlying mechanisms. Following the era in which the emphasis was very much on describing the clinical, cognitive and behavioural signs of the disease, the last two decades have been marked by the incredibly rapid development of neuroimaging techniques and the gradual establishment of relationships between neuroimaging and cognitive manifestations. The time has now come to combine complementary neuroimaging findings. While there have already been some tentative attempts at an integrative model (e.g. Buckner et al., 2005), longitudinal multimodal studies are now needed if we are to enhance our understanding of these AD-related changes still further and effectively gauge the impact of new and promising treatments.

Francis Eustache

Inserm - EPHE - Université de

Caen Basse Normandie

Unité de Recherche U923

"Neuropsychologie Cognitive et

Neuroanatomie Fonctionnelle de la

Mémoire Humaine"

Laboratoire de Neuropsychologie

CHU, Avenue de la Côte de Nacre

14033 - Caen cedex

Tel : +33231065197

Fax : +33231065198

email: neuropsycho@chu-caen.fr

URL: emi.cyceron.fr
\& Gaël Chételat

Inserm - EPHE - Université de

Caen Basse Normandie

Unité de Recherche U923

Centre Cyceron

Bd H. Becquerel

BP 5229

14074 CAEN Cedex

Tel : +33231470107

Fax : +33231470275

email: chetelat@cyceron.fr

Alzheimer, A. (1907). Uber eine eigenartige Erkrankung der Hirinde. Allgemeine Zeitschrift für Psychiatrie und psychisch-Gerichtliche Medizin, 64, 146-148.

Jucker, M., Beyreuther, K., Haass, C., Nitsch, R., \& Christen, Y. (2006). Alzheimer: 100 Years and Beyond. Berlin Heidelberg: Springer.

Eustache, F., \& Desgranges, B. (2008). MNESIS: Towards the Integration of Current Multisystem Models of Memory. Neuropsychology review, in Press.

Hodges, J.R. (2006). Alzheimer's centennial legacy: origins, landmarks and the current status of knowledge concerning cognitive aspects. Brain, 129(Pt 11), 2811-2822.

Heindel, W.C., Salmon, D.P., Shults, C.W., Walicke, P.A., \& Butters, N. (1989). Neuropsychological evidence for multiple implicit memory systems: a comparison of 
Alzheimer's, Huntington's, and Parkinson's disease patients. The Journal of neuroscience, 9(2), 582-587.

Gainotti, G., \& Marra, C. (1994). Some aspects of memory disorders clearly distinguish dementia of the Alzheimer's type from depressive pseudo-dementia. Journal of clinical and experimental neuropsychology, 16(1), 65-78.

Buckner, R.L., Snyder, A.Z., Shannon, B.J., LaRossa, G., Sachs, R., Fotenos, A.F., et al. (2005). Molecular, structural, and functional characterization of Alzheimer's disease: evidence for a relationship between default activity, amyloid, and memory. The Journal of neuroscience, 25(34), 7709-7717. 